\section{PHYSICIST'S VIEW OF NATURE}

\section{Physics}

Its Structure and Evolution. By Williarn A. Blanpied. (A Blaisdell Book in the Pure and Applied Sciences.) Pp. xix +950. (Blaisdell: Waltham, Massachusetts and London, 1969.) \$13.50.

The planning of courses in physics for liberal arts students has been a growth industry in American universitics during recent years. An observer of the development soon recognizes that the term "liberal arts student" embraces a broad human spectrum which includes some who are capable of benefiting from high grade courses in physics. It is for such students that this book is designed. Based on work done by the author at Yale and later at Case Western Reserve University, the book is concerned with the physicist's view of nature and, in Feynman's phrase, his "quest for the rules of the game". Dr Blanpied has concentrated on topics of contemporary interest, including the search for a pattern in elementary particle physics and the role of symmetry. He provides major treatments of classical Newtonian mechanics, of special relativity and of quantum mechanies. His concern is to show how physies and its theories have evolved and how they continue to cvolve. His aims are arnbitious and sacrifices have been accepted in order to attain them. There is no account of the dynamies of rigid bodies, whilst geometrical optics and electrical circuitry receive the same scant attention which is paid to the applications of physics. The criterion for such selection has been, consistently, tho nocd of a liberal arts student with a genuine desire to work at the subject of physics as a fundamental part of his studies of entemporary culture.

Believing that physics itself is more concerned with mathematical ideas than with mathematical techniques, Blanpied assumes a background of high school mathematics and introduces the idea of the derivative, using numerical methods for the solution of differential equations when this is required.

The result is as cxciting in its field as were the Feynman lectures in another. In Britain the book may find an application in the needs of the tiny handful of students currently studying physies as a component of the Bachelor of Education degree. It may also mect the needs of some general degree students in their first year. For a physics teacher with his eye on a future which embraces a new Nuffield A-level physics cour'se as well as Q- and $F$. levels, this deseription of somo part of physics as it is soon today will bo a considerable asset. Alas that it should be so highly priced.

E. J. WENHAM

\section{INTRODUCTION TO MICROWAVES}

\section{Microwaves}

By A. J. Baden Fuller. (The Cornmonwealth and International Library of Science, Tcchnology, Engineering and Liberal Studies: Applied Electricity and Electronics Division.) Pp. $x v+289$. (Pergamon: Oxford, London and New York, November 1969.) 48s (\$7.50) hard cover; $35 s(\$ 5.50)$ flexi-cover.

ABour half of this book is devoted to an clementary account of transmission line and waveguide theory. The first chapter covers transmission-line theory, with emphasis on high-frequency operation and includes a brief treatment of stub-matching and the quarter-wave transformer. A briof second chapter on electromagnetic fields collects the important formulae and discusses the plane TFM wave. The next two chapters deal respectively with rectangular and circular waveguides. The expressions for tho field components and the cut-off frequencies are derived in a simple and direct manner, and this part of the book is likely to be of real value to the undergraduate student in learning basic waveguide theory.
The next three chapters deal largely with plane-wave propagation in conducting media, ferrites and plasmas. Plane waves in magnetized ferrites and plasmas are studied briefly and waveguide applications mentioned. Spacecharge waves on electron beams are outlined in three and a half pages.

The rest of the book (pages 195-263) is devoted to a sketchy outline of microwave techniques. It refers briefly to klystrons, magnetrons, travelling-wave tubes, masers, paramps, harmonic generators, Gunn oscillators, bends, twists, directional couplers, T-junctions, and the like, leading finally to a chapter on microwave measurements. The treatment is sound and includes reference to many modern devices and techniques, but it does not claim to do more than provide a background, of an almost completely non-mathematical kind, to the theory of the earlier chapters. The book concludes with a bibliography, a collection of worked examples (there are also problems after each of the first eight chapters) and three brief appendices.

It is perhaps unfair to criticize the book for omitting so much; cavity resonators are hardly considered, detailed attenuation and Q-factor calculations are omitted, there is no theoretical discussion of discontinuitics, inductive and capacitive diaphragms are not mentioned and the concept of the scattering matrix does not appear. There is in fact no discussion at all of even elementary microwave network theory. In my opinion, the advantage gained by treating the conducting media along with ferrites and plasmas doos not outweigh the disadvantage of needing the material (and having to refer to it) much earlier in the book. But apart from this small eriticism, the exposition is usually very good. A simple and direct approach is always used, and the mathematical theory, which some undergraduates find difficult, is here presented in the clearest and simplest manner possible.

Within its limited scope, the book will be found helpful to those approaching tho subject of microwaves for the first time.

A. L. CULIFN

\section{AURORA AND AIRGLOW}

\section{Atmospheric Emissions}

Edited by Billy M. McCormac and Anders Omholt. (Proceedings of the NATO Advanced Study Institute held at the Agricultural College of Norway, As, Norway, July 29-August 9, 1968.) Pp. xi +563 . (Van Nostrand Reinhold: New York and London, November 1969.) $234 s$.

THIs book confronts us with a large collection of papers on the subjects of aurora and airglow given at a NATO Advanced Study Institutc. The speed with which these proceedings have been published is commendable and this gives the book a great deal of its value. It is intended for the specialist and will bc useful for scientists working in the fields of aeronomy, ionospheric physics, energetic particles, space communications, optical sensors, the Earth's magnetosphere, global weather and in the ficlds of rocket, balloon and satellite moasurements of aurora, airglow and the spaco environment.

Study institutes on aurora and airglow aro usually hold by NATO every two years and it is interesting to consider the progress made during the two years betwoen the institute at Keele, England, and this one at Âs, Norway. The major difference is due to a refinement of experimental technique, both on tho ground, where photoelectric imaging devices such as intensifying image orthacons and vidicons are becoming commonplace, and in the air, where satellites aro now carrying improved low encrgy particle detcctors, and electric and magnctic field detectors. This acquisition of more precise data has had an effect on the permissible theories. The basic concepts of 